DOI: 10.4274/tod.37928

Turk J Osteoporos 2017;23:29-32

\title{
Bilateral Tibia Fibula Kırı̆ı̆ı Sonrası Kompleks Bölgesel Ağrı Sendromu
}

\author{
Bilateral Complex Regional Pain Syndrome after Fracture of Bilateral Tibia and Fibula
}

Senem Şaş, Zeynep Karakuzu Güngör*, Hatice Rana Erdem*, Figen Tuncay*

Ahi Evran Üniversitesi Eğitim ve Araştırma Hastanesi, Fiziksel Tıp ve Rehabilitasyon Kliniği, Kırşehir, Türkiye

${ }^{*}$ Ahi Evran Üniversitesi Tıp Fakültesi, Fiziksel Tıp ve Rehabilitasyon Anabilim Dalı, Kırşehir, Türkiye

\section{$\ddot{O z}$}

Kompleks bölgesel ağrı sendromu tip 1 (KBAS-1) ağrılı bir olaydan sonra ortaya çıkan allodini, hiperaljezi, ödem, deri kan akımında anormallik ve anormal sudomotor aktivite bulgularıla karakterize ağrılı bir klinik durumdur. Sinir yaralanması olduğunda ise KBAS-2 olarak kategorize edilmektedir. KBAS-1 etiyopatogenezinde santral ve periferal mekanizmal sorumlu tutulmaktadır. KBAS-1 genellikle hasarlanan ekstremitede ortaya çıkar. Ancak, bazen karşı ekstremitede de görülebilir. Bu yazıda bilateral tibia fibula kırı̆̆ı sonrası bilateral KBAS-1 gelişen bir olguyu güncel literatür eşliğinde sunmaktayız.

Anahtar kelimeler: Kompleks bölgesel ağrı sendromu, bilateral, kırık

\section{Abstract}

Complex regional syndrome type 1 (CRPS-1) is a painful clinical condition. It occurs after a painful event and characterized by allodynia, hyperalgesia, edema, abnormalities in skin blood flow and abnormal sudomotor activity. When CRPS-1 is associated with nerve injury, it is defined as CRPS-2. Central and peripheral theory are responsible in etiopathogenesis of CRPS-1. Generally it occurs in the injured limb. But, it may ocur in the opposite extremities. In this article, we present a case developing bilateral CRPS-1 after bilateral tibia and fibula fracture by reviewing current literatüre.

Keywords: Complex regional pain syndrome, bilateral, fracture

\section{Giriş}

Kompleks bölgesel ağrı sendromu tip 1 (KBAS-1) ağrılı bir olaydan sonra ortaya çıkan allodini, hiperaljezi, ödem, deri kan akımında anormallik ve anormal sudomotor aktivite bulgularıyla karakterize ağrılı bir klinik durumdur (1). Bazı kişilerde kendini sınırlayan bir durumken, bazılarında dizabiliteye neden olabilmektedir (2). Yalnızca bir periferik sinir bölgesinde sınırlı olmayıp, başlatan olayla orantısız bir ağrı sıklıkla görülmektedir. Genellikle ekstremiteler etkilenirken sempatik sinir sisteminde disfonksiyon ve şiddetli nöropatik ağrı görülür (3). Çoğunlukla travma veya cerrahiyi takiben gelişirken, literatürde idiyopatik olgular da bildirilmiştir (3). KBAS-1 gelişiminde genetik yatkınlık olabileceği öne sürülmektedir (4). Erişkinlerde üst ekstremite daha sık etkilenirken, çocuklarda alt ekstremite daha sık etkilenmektedir (1). KBAS-1'in hasarlanan ekstremitede unilateral ortaya çıkması beklenir. Bilateral KBAS-1 daha az sıklıkta ve genellikle alt ekstremitede görülür. Bu yazıda bilateral tibia-fibula kırı̆ı sonrası bilateral KBAS-1 gelişen olgu güncel literatür eşliğinde tartışılmıştır.

\section{Olgu Sunumu}

Kırk üç yaşındaki inşaat işçisi erkek hasta her iki ayak bileğinde şiddetli ağrı, şişlik, kızarıklık, hassasiyet, hareket kısıtılığı, yürüyememe şikayeti ile polikliniğimize başvurdu. Üç ay önce inşaatta çalışırken 7 metre yükseklikten düşme sonrası bilateral tibia ve fibula fraktürü geliştiği, bir gün sonra ortopedi ve travmatoloji kliniği tarafından opere edildiği öğrenildi. Ameliyat sonrasında her iki alt ekstremiteye kısa bacak alçısı uygulanmıştı. Sol alt ekstremite alçısı 25 gün, sağ alt ekstremite alçısı 45 gün kadar kaldıktan sonra çıkarılmış ve hastaya sol ayak bileğine 60 gün yük vermemesi, sağ ayak bileğine 100 gün yük vermemesi önerilmişti. Ancak bu süre içerisinde hastada her iki ayak bileğinde şiddetli ağrı, şişlik ve kızarıklık şikayetleri başlamış ve yürüyemez

Yazışma Adresi/Address for Correspondence: Dr. Senem Şaş, Ahi Evran Üniversitesi Eğitim ve Araştırma Hastanesi, Fiziksel Tıp ve Rehabilitasyon Kliniği, Kırşehir, Türkiye Tel.: +90 5055520451 E-posta: senemsas@gmail.com Geliş Tarihi/Received: 01.08.2016 Kabul Tarihi/Accepted: 03.04.2017 
olmuştu. Hastanın özgeçmişinde çocukluğunda geçirdiği klavikula kırığı ve 2 kez geçirdiği sol el metakarp kırığı öyküsü mevcuttu. Lökomotor sistem muayenesinde her iki ayak bileği ve parmak hareketleri ileri derecede kısıtlı ve ağrılı idi. Her iki ayak sırtı ve parmaklarda belirgin ödem, sıcaklık artışı ve palpasyonla hassasiyet tespit edildi. Hasta ayaklarındaki şiddetli ağrısı ve hareket kısıtlığı nedeniyle tekerlekli sandalyeyle ambuleydi. Hastaya bu muayene bulguları ile KBAS-1 ön tanısı konularak kliniğimize hastanın yatışı sağlandı. Hastanın laboratuvar incelemesinde eritrosit sedimantasyon hızı: $3 \mathrm{~mm} / \mathrm{h}$, C-reaktif protein: 0,39 mg/dL, hemoglobin: 16,4 g/dL, WBC: 9,09 103, biyokimyasal testler normal sınırlardaydı. Hastanın yapılan kemik dansitometresinde L1-L4 T skoru -0,9 olarak geldi. Klinik ve laboratuvar bulgularıyla bilateral tibia fibula kemik kırığına bağlı olarak gelişen hastaya KBAS-1 tanısı konuldu (Resim 1-3). Hasta ortopedi kliniğince tekrar konsülte edildi kallus dokusu tam olarak oluşmadığından hastanın ayak bileklerine bilateral kısmi ağırlık verilerek, egzersiz programına başlandı. Hastaya medikal tedavi olarak intramusküler kalsitonin, nonsteroid anti-enflamatuvar, kalsiyum-D vitamini tedavisi uygulandı. Ayrıca, hastanın her iki ayak bileğine diadinamik akım, whirlpool, transkutanöz elektriksel sinir stimülasyonu (TENS), eklem hareket açıklık egzersizleri, germe egzersizleri, yürüme eğitimi denge koordinasyon eğitimi başlandı. Takiplerinde her iki ayağında nöropatik ağı tarifleyen hastanın tedavisine pregabalin eklendi. Doz kademeli olarak 225 mg/güne çıkıldı. Hastamızın klinik takibinde semptomlarında belirgin düzelme oldu. Ayak bileği eklem hareket açıklığında artma kaydeden, ağrıları kalmayan hasta ayak bileğine uygulayacağı yükü giderek artırması planlanarak koltuk değnekleriyle ambule şekilde, pregabalin, kalsiyum ve D vitamini tedavisine üç ay süre ile devam edilmesi önerisiyle taburcu edildi. Hastanın üç ay sonraki kontrolünde ağrı ve ödemin kaybolduğu ve bağımsız olarak ambule olduğu gözlendi.

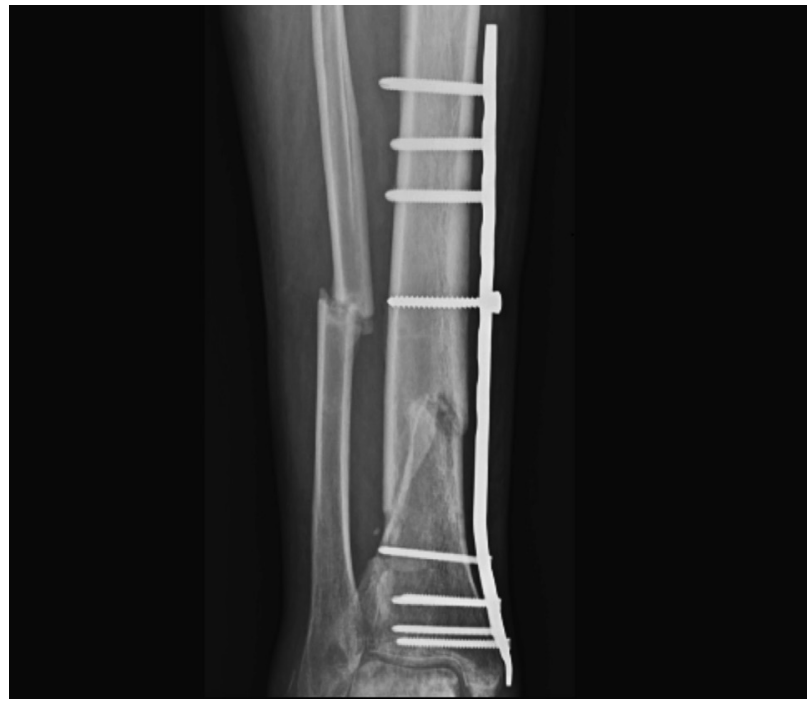

Resim 1. Sağ alt ekstremitede tibia ve fibula fraktürü

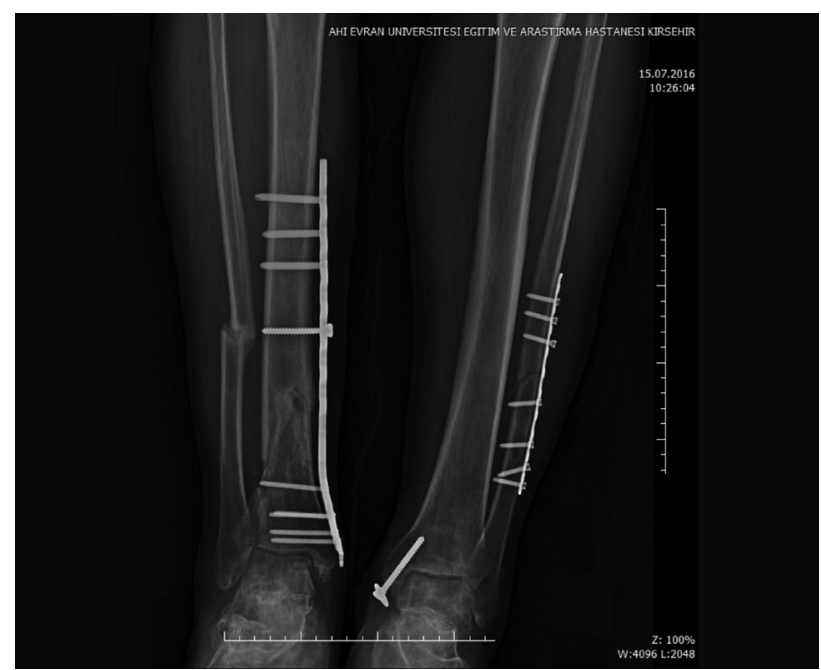

Resim 2. Olgunun sağ ve sol tibia ve fibula fraktürünü gösteren grafi

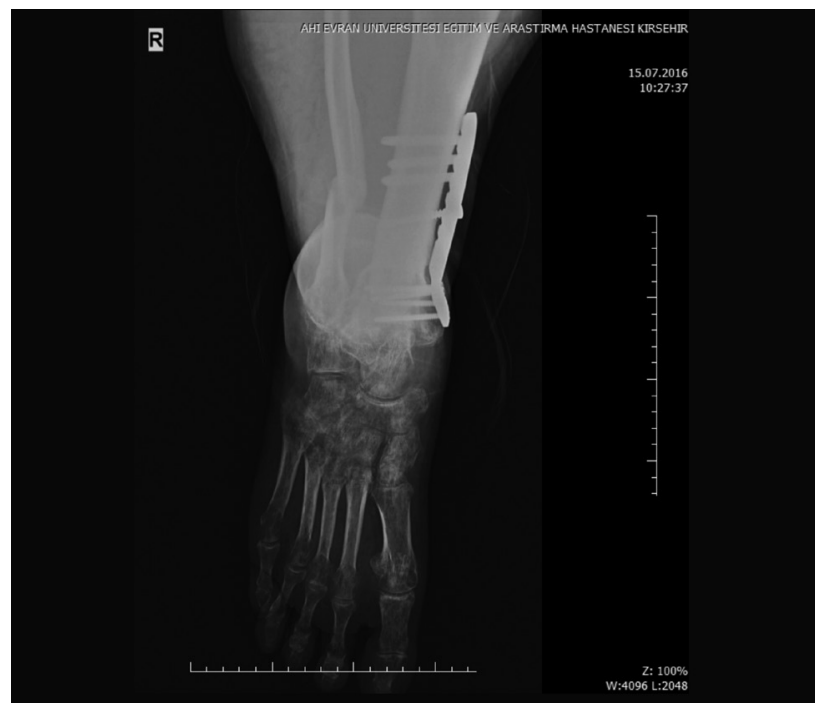

Resim 3. Benekli osteoporoz

\section{Tartışma}

KBAS-1 etiyopatogenezi tam olarak anlaşılamasa da kırıklar başta olmak üzere travma, santral sinir sistemi hastalıkları, serebrovasküler olaylar ve periferiknöropati gibi durumlar sorumlu tutulmaktadır. KBAS'da periferik aksonal adrenoreseptörlerin sayısında veya duyarlılığında artış, sempatik denervasyona bağlı olarak katekolaminlere karşı artmış duyarlılık olduğu düşünülmektedir. Bundan başka, primer nosiseptif afferentler ve sempatik efferentlerden nöropeptidlerin (substans $P$, kalsitonin gen ilişkilipeptid ve nöropeptid Y) salınımı ile nörojenik enflamasyon gelişmesi gibi mekanizmalarda öne sürülmektedir. Bu durum klinik olarak hiperaljezi ve allodinin geliştiği santral duyarlılıkla sonuçlanır $(1,4)$.

KBAS'ta sempatik sistemin tutulumu ağrı ve dizabilite nedeni olabildiği gibi dizabiliteye yanıt olarak da meydana gelebilir. 
Beyin damar hastalıklarında vazomotor ve sudomotor belirtilerin ağrı olmadan gelişmesi sempatik sinir etkilenmesi olmadan da ortaya çıkabileceğini göstermektedir (5).

KBAS insidansı kırıklardan sonra \%1-2, Colles kırığı sonrası \%7-35 olarak bildirilmiştir (6). Travma merkezlerine başvuran hastaların iki binde birinde KBAS gelişme intimali mevcuttur. Periferik sinir lezyonlarından sonra \%3, hemipleji hastalarında \%10, travmatik beyin yaralanmalarından sonra $\% 13$, miyokard infarktüsünden sonra \%22 oranında KBAS gelişebilir (7). Olguların \%90’ KBAS1 iken, geri kalan bölümü periferal sinir lezyonlarının eşlik ettiği KBAS-2'dir (kozalji) (2).

KBAS klinik bulgularının travmadan 6 ay sonra çıkması beklenir. Genellikle distal tutulum görülür ve tek taraf etkilenir. Üst ekstremitenin alt ekstremiteye göre daha sık etkilendiği bildirilmiştir (1). KBAS tüm yaş gruplarında görülebilirken, olguların \%60-80'i kadındır (8). Literatürde belirtilen en genç olgu 2,5 yaşındadır (9). Çocuklarda sol ekstremite ve alt taraf tutulumun daha fazla görüldüğü raporlanmış bununla birlikte kız çocuklarında ve 12 yaşta daha sık görüldüğü vurgulanmıştır (6). Kadınlarda sık görülmesi östrojen bağımlı ağı yanıtlarının veya psikolojik sorunlardan kaynaklanmasına bağlanmaktadır (10). KBAS'lı hastaların depresyona yatkın kişiler olduğu düşünülmesine karşın birçok çalışmada KBAS nedeniyle depresyonun meydana geldiği yayınlanmıştır (8). Ayrıca genetik yatkınlık araştııımış ve bazı insan lökosit antijen (HLA) lokusları ile arasında ilişki saptanmıştır. HLA-B62, HLA-DQ8, HLA-DQ1, HLA-DR13 ve HLADR2'nin KBAS'da enflamasyona ve nöroplastisite regülasyonuna katkıda bulunuyor olabileceği yayınlanmıştır $(4,6)$.

KBAS-1 genellikle hasarlanan ekstremitede görülür. Ancak diğer ekstremitelerde de görülebilir. Bilateral KBAS ilk kez Livingstone tarafından 35 olguda rapor edilmiştir (11). 1183 KBAS-1 olgunun incelendiği bir çalışmada 10 tanesinde bilateral olduğu yayınlanmıştır (12). Yıldız ve ark. (13) ise lomber disk hernisi nedeniyle bilateral KBAS gelişen ve konservatif tedavilere yanıt veren bir erkek olgu tanımlamışlardır.

Sandroni ve ark. (14) birden fazla ekstremite tutulum oranını \%4 olarak bildirmişlerdir (14). Kurvers ve ark. (15) KBAS kliniği olmadan karşı ekstremitede kan akım hızında simetrik artış olduğunu göstermişlerdir. Van'dan yayınlanan bir raporda bilateral kalkaneus kırığı sonrası gelişen bilateral KBAS'lı bir olgu sunulmuştur (16). Altındağ ve ark. (17) ise sol distal tibia fraktürü sonrası tedaviye dirençli bilateral KBAS olgu sunumu yapmışlardır. Bizim olgumuz ise bilateral tibia fibula kırığı sonrası bilateral KBAS-1 gelişen 43 yaşındaki erkek hasta idi. Olgumuzda kırık öncesinde KBAS-1'e yatkınlık oluşturacak ilaç kullanımı ya da pskiyatrik hastalık öyküsü yoktu. Bilateral KBAS-1 gelişimi bilateral kırık ve genetik yatkınlığa bağlı olabilir.

KBAS tanısı primer olarak klinik ile konur. Kullanılan tanı yöntemleri arasında radyoloji, sintigrafi, magnetik rezonans (MR), termografi ve elektromiyografi bulunmaktadır. Erişkinde radyolojik görüntüleme ile benekli osteoporoz saptanabilir. Ancak bu görüntü hastalığın geç döneminde ortaya çıkar ve spesifik değildir. Sintigrafide erken evrede artmış tutulum tipiktir (4). Olgumuzun tanısı tipik klinik tablo ve direkt grafi ile konulmuş, tanı için sintigrafi, MR gibi yöntemlere gerek duyulmamıştır.

KBAS-1'in tedavisi medikal olarak ve fizik tedavi modaliteleri ile yapılmaktadır. Medikal tedavide sıklıkla nonsteroid anti-enflamatuvar ilaçlar, kortikosteroid, narkotik analjezikler, sempatolitik ilaçlar, alfa ve beta blokerler, postganglionikblokerler, kalsiyum kanal blokerleri, trisiklik antidepresanlar, antikonvulzanlar, kalsitonin ve bifosfonatlar kullanılmaktadır. Ayrıca serbest radikal temizleyici (dimetilsülfoksit-DMSO ve N-asetilsistein-NAC ve vazodilatör (verapamil, ketanserin veya pentoksifilin tedavilerinin yararlı olduğuna dair çalışmalar mevcuttur (4). Bunun yanı sıra elektrokonvulzif tedavi, intravenöz ketamin ve intravenöz immünglobülin uygulamalarının KBAS tedavisinde faydalı olduğu rapor edilmiştir (4). Günlük 500-1000 mg C vitaminin 50 gün süre ile alınmasının KBAS gelişimini önlemede faydalı olduğuna dair kanıt mevcuttur (18).

Hastalığın fizik tedavi yöntemleri ile tedavisinde ise hastalığın dönemine göre ekstremite elevasyonu, kontrast banyo (sıcaksoğuk uygulamaları), hidroterapi, elektroterapi (transkütan elektriksel sınır stimülasyonu, diadinamik akım, interferansiyel akım) eksternal pnömotik kompresyon, egzersiz, akupunktur, masaj, splintleme ve ayna tedavisi gibi modaliteler yer almaktadır. Dirençli olgularda girişimsel tedavilerden yararlanılmaktadır. Sempatik blok uygulamalarının KBAS tedavisinde kullanıldığına dair yayınlar bulunmaktadır. Intravenöz rejyonel anestezi yöntemi ile guanitidin, bretilyum, klonidin, droperidol, ketanserin, rezerpin ile ilgili çalışmalar bulunmaktadır. Guanitidinin etkinliğine dair orta düzeyde kanıt bulunmaktadır (19). Ayrıca plazma değişiminin KBAS tedavisinde yararlı olduğu raporlanmıştır (20). Sigarayı bırakmanın KBAS iyileşmesinde olumlu katkı sağlayabileceği bildirilmiştir (21). Katznelson ve ark. (22) ise 41 yaşında sol ayak bileğinde kırık sonrası KBAS gelişen bir hastada üç haftalık hiperbarik oksijen tedavisinin yararlı olduğunu vurgulamışlardır. Cerrahi tedavi dirençli olgularda, kontraktür gelişenlerde denenebilir. Tenoliz, kapsülotomi, fasyotomi, ligaman serbestleştirilmesi, kortikal rezeksiyon ve ampütasyon cerrahi yöntemler arasındadır. Ampütasyon, tekrarlayan enfeksiyon veya dirençli olgularda rezidüel fonksiyonu iyileştirmek için denenebilir (4).

Bizim olgumuzun tedavisinde ise medikal tedavi olarak kalsitonin, non-steroid anti-enflamatuvar, kalsiyum ve $D$ vitamini, fizik tedavi yöntemlerinden ise kontrast banyo, whirlpool, diadinamik akım ve sonrasında TENS ve ayrıca egzersiz programı uygulanmış, ağrı kontrolü yeteri kadar sağlanamayınca pregabalin tedavisi ilave edilmiştir.

Sonuç olarak; bilateral KBAS gelişimi oldukça nadir görülür. Bununla birlikte bizim olgumuzda olduğu gibi bilateral yaralanmalarda birden fazla ekstremitede KBAS gelişim intimali akılda tutulmalıdır. Erken tanı uygun tedavi prosedürlerinin başarısı için gereklidir.

\section{Etik}

Hasta Onayı: Alınmıştır. 
Hakem Değerlendirmesi: Editörler kurulu ve editörler kurulu dışında olan kişiler tarafından değerlendirilmiştir.

\section{Yazarlık Katkıları}

Cerrahi ve Medikal Uygulama: S.Ş., Konsept: S.Ş., Dizayn: S.Ş., H.R.E., F.T., Veri Toplama veya İşleme: S.Ş., Z.K.G., Analiz veya Yorumlama: S.Ş., Literatür Arama: Z.K.G., Yazan: S.Ş.

Çıkar Çatışması: Yazarlar tarafından çıkar çatışması bildirilmemiştir.

Finansal Destek: Yazarlar tarafından finansal destek almadıkları bildirilmiştir.

\section{Kaynaklar}

1. Schwartzman RJ, Erwin KL, Alexander GM. The natural history of complex regional pain syndrome. Clin J Pain 2009:25:273-80.

2. Costigan M, Scholz J, Woolf CJ. Neuropathicpain: A maladaptive response of the nervous system to damage. Annu Rev Neurosci 2009;32:1-32

3. Casale R, Atzeni F, Sarzi-Puttini P. From Mitchell's causalgia to complex regional pain syndromes: 150 years of definitions and theories. Clin Exp Rheumatol 2015;33(1 Suppl 88):7-13.

4. Ganty P, Chawla R. Complex regional pain syndromes. Continuing education in anaesthesia. Crit Care Pain 2014;14:79-84

5. Irdesel J. Omuz ağrısı. In: Özcan O, İrdesel J, Sivrioğlu K, editors. Kas iskelet sistemi ağrıları. İstanbul:Nobel tıp Kitabevleri, 2005,246-52.

6. Weissmann R, Uziel Y. Pediatric complex regional pain syndrome: a review. Pediatr Rheumatol Online J. 2016;14:29.

7. Möhür H. Refleks Sempatik Distrofide Etyopatogenez, Türk Fiz Tıp RehabDerg 2001;47(Özel):81-6.

8. Stanton-Hicks M. Complex regional pain syndrome. Anesthesiol Clin North Am 2003;21:733-44

9. Güler-Uysal F, Başaran S, Geertzen JH, Göncü K. A 2 1/2-year-old girl with reflex sympathetic dystrophy syndrome (CRPS type I): case report. Clin Rehabil 2003:17:224-7.
10. Akbaş M, Yeğin A, Karslı B. Reflex sympathetic dystrophy in a 10 year old pediatric patient: case report. Turkiye Klinikleri J Anest Reanim 2008;6:87-90.

11. Livingstone WK. Painmechanisms. A Physiologic Interpretation of Causalgia and Its Related States. New York: Plenum Press, 1976.

12. Veldman PH, Goris RJ. Multiple reflex sympathetic dystrophy. Which patients are at risk for developing a recurrence of reflex sympathetic dystrophy in the same or another limb. Pain 1996;64:463-6

13. Yıldız N, Gungon GO, Yaylalı O, Ardic F. Bilateral complex regional painsyndrome associated with lumbar disc herniation. Turkish Journal of Rheumatology 2011;26:66-71.

14. Sandroni P, Benrud-Larson LM, McClelland RL, Low PA. Complex regional painsyndrome type $\mathrm{I}$ : incidence and prevalence in Olmsted county, a population-based study. Pain 2003;103:199207.

15. Kurvers HA, Jacobs MJ, Beuk RJ, van den Wildenberg FA, Kitslaar PJ, Slaaf DW, et al. Theinfluence of local skin heating and reactive hyperaemia on skin blood flow abnormalities in patients with reflex sympathetic dystrophy (RSD). Eur J ClinInvest 1995:25:34652.

16. Hız O, Ediz L, Ceylan MF, Gülcü E, Tekeoğlu I. Bilateral kalkaneus kırığı sonrasında bilateral kompleks bölgesel ağrı sendromu: Olgu sunumu. Osteoporoz Dünyasından 2010;16:38-40.

17. Altındağ Ö, Aydeniz A, Gürsoy S, Bukan TH. Bilateral ayak tutulumu gösteren tedaviye dirençli kompleks bölgesel ağrı sendromu tip 1: Bir olgu sunumu. Turk J Rheumatol 2009:24;1035.

18. Palmer G. Complex regional pain syndrome. Aust Prescr 2015;38:82-6.

19. Özyalçın S, Dinçer S. Kompleks Rejyonal Ağrı Sendromu. Archives of Neuropsychiatry/ Noropsikiatri Arsivi 2009;46.

20. Aradillas E, Schwartzman RJ, Grothusen JR, Goebel A, Alexander GM. Plasma Exchange Therapy in Patients with Complex Regional Pain Syndrome. Pain Physician 2015;18:383-94

21. Carr ES, De Larda Cerda A, Fiala K. Complex regional pain syndrome. Proc (Bayl Univ Med Cent) 2016;29:333-4.

22. Katznelson R, Segal SC, Clarke H. SuccessfulTreatment of Lower Limb Complex Regional Pain Syndrome following Three Weeks of Hyperbaric Oxygen Therapy. Pain Res Manag 2016;2016:3458371. 